\title{
Permanent Deformation and Rutting Resistance of Demolition Waste Triple Blends in Unbound Pavement Applications
}

\author{
Farshid Maghool ${ }^{1, *}$, Muditha Senanayake ${ }^{1}$, Arul Arulrajah ${ }^{1}$ and Suksun Horpibulsuk ${ }^{1,2, *}$ (D) \\ 1 Department of Civil and Construction Engineering, Swinburne University of Technology, \\ Melbourne 3122, Australia; ssenanayake@swin.edu.au (M.S.); aarulrajah@swin.edu.au (A.A.) \\ 2 School of Civil Engineering, and Center of Excellence in Innovation for Sustainable Infrastructure \\ Development, Suranaree University of Technology, Nakhon Ratchasima 30000, Thailand and Academy of \\ Science, The Royal Society of Thailand, Bangkok 10300, Thailand \\ * Correspondence: fmaghool@swin.edu.au (F.M.); suksun@g.sut.ac.th (S.H.)
}

Citation: Maghool, F.; Senanayake, M.; Arulrajah, A.; Horpibulsuk, S. Permanent Deformation and Rutting Resistance of Demolition Waste Triple Blends in Unbound Pavement Applications. Materials 2021, 14, 798. https://doi.org/10.3390/ma14040798

Academic Editor: Francesca Ceroni

Received: 18 January 2021

Accepted: 3 February 2021

Published: 8 February 2021

Publisher's Note: MDPI stays neutral with regard to jurisdictional claims in published maps and institutional affiliations.

Copyright: (c) 2021 by the authors. Licensee MDPI, Basel, Switzerland. This article is an open access article distributed under the terms and conditions of the Creative Commons Attribution (CC BY) license (https:/ / creativecommons.org/licenses/by/ $4.0 /)$.
Abstract: Virgin quarried materials are becoming increasingly scarce in our environment, and these materials are no longer a viable or economical solution for the construction industry. The construction industry is constantly seeking new markets for recycled waste in civil engineering applications. This research's primary focus is the optimization of the usage of recycled materials such as recycled glass (RG), crushed brick (CB), and crushed concrete (CC), in pavement base/sub-base applications. Various percentages of RG, up to $40 \%$, were blended with two types of CC in this research. The CC and $C B$, which were used as triple blends in this research, were utilized for the upper $(100 \% \mathrm{CC})$ and lower sub-bases (up to $50 \% \mathrm{CB}$ ). This study sought to establish the maximum amount of RG that could be incorporated in the triple blends with CB and CC whilst maintaining an acceptable performance. Thus, a comprehensive series of fundamental and advanced geotechnical laboratory tests, including repeated load triaxial (RLT) and wheel-tracker (WT) tests, were performed to assess the engineering properties and permanent deformation characteristics of these triple blends. The particle-size distribution curve and California Bearing Ratio (CBR) values of all the blends met the minimum requirements. Results of RLT tests confirmed that all the nominated blends were found to provide the resilient modulus value required to be used as pavement materials. The WT results on the triple blend with 15\% RG showed that the specimen performed exceptionally well during the test and comfortably met the requirements to be used in pavement applications. Based on the engineering properties and permanent deformation results, up to $15 \%$ RG can be suggested for incorporation as an accompanying material in unbound roadwork applications. Subject to the outcomes of future field testing, there might be potential to increase the percentage of RG added in the blends up to $30 \%$.

Keywords: pavement base; permanent deformation; wheel-tracker; rutting; demolition wastes; ground improvement

\section{Introduction}

The use of natural resources in major construction projects is not only costly, but increasingly unsustainable. Natural resources are becoming very limited in supply, which is detrimental to the environment. In recent years, researchers have established that recycled materials can offer improved performance, and in some cases, more durability compared to virgin quarried materials [1]. This direction, using recycled materials instead of virgin materials, will inevitably reduce landfills and carbon footprint. Effectively employing recycled materials is a viable sustainable solution, ultimately retaining natural resources [2].

In recent years, the disposal of solid waste has become a major problem, and has become increasingly expensive. Waste levies are imposed and intended by state governments in Australia to support moving waste materials from landfill to recycling [3]. For instance, levies for disposal at landfill in Australia's major cities for municipal solid waste are around AUD\$90 per ton, for construction and industrial waste they are AUD\$146 per ton, and 
levies for mixed waste are AUD $\$ 199$ per ton [3]. Even recycling plants are accumulating large stockpiles of recycled materials.

The designers and relevant authorities for infrastructure projects globally have, until now, favored working with naturally occurring materials. Before they can accept any new materials, the performance and service life of these recycled materials need to be carefully tested under simulated traffic loading, and different environmental and climatic conditions. The determination of critical parameters such as the resilient modulus and permanent deformation, using the repeated load triaxial (RLT) test is of increasing interest to design engineers and decision makers. Rutting resistance is one of the main concerns in pavement design. Rutting can occur due to the continued growth of permanent deformation during the lifetime and serviceability of the pavement structure [4]. Meeting the requirements for good resistance rutting in granular layers is more difficult than developing an acceptable resilient modulus [5]. The wheel-tracker (WT) test can provide an accurate estimation of rutting for designers and simulate real traffic loading on pavement.

To date, several attempts have been made to substitute virgin materials with recycled materials such as construction and demolition materials including recycled glass (RG) [6,7], crushed concrete (CC) [8,9], crushed brick (CB) [10,11], crushed waste rock [12,13], recycled plastics [14,15], reclaimed asphalt pavement [16,17], biosolids [18], coffee [19], crumb rubber [20,21], light-weight foamed glass [22], and different types of slags [23-25]. Lately, significant volumes of these materials have been well-utilized as new construction materials in different applications, such as typical civil, pipe bedding, rural road, and fill applications.

Some studies have shown that up to $20-25 \%$ RG can be added to natural unbound material without substantial effects on the mechanical behavior of base course layers [26]. Some research proved that up to $25 \%$ CB could be securely added to CC and crushed-rock blends in pavement unbound sub-base applications [27]. Some studies permitted up to $50 \%$ CB content for sub-base applications after treating with 3\% cement [28].

In the state of Victoria alone, approximately 300,000 tons of RG, 1.4 million tons of $\mathrm{CB}$, and 3.5 million tons of $\mathrm{CC}$ are available for processing per annum. $\mathrm{RG}, \mathrm{CC}$, and $\mathrm{CB}$ are well-known recycled materials in the construction industry. These materials have been shown to exhibit promising results in regard to engineering properties and have the potential to substitute natural quarry in a number of road applications [29,30]. Assessments of the environmental risks of RG, CC, and CB have also been conducted and compared to environmental protection policies. These materials were determined not to exhibit any leaching hazards during their service life in roadwork applications [29,30]. This study proposes to investigate the use of RG (up to $40 \%$ ) with two types of CC in upper (100\% CC) and lower sub-bases (comprising up to $50 \% \mathrm{CB}$ ) as triple blends in unbound roadwork applications. This study seeks to establish a new standard figure for the maximum amount of crushed glass that can be incorporated in triple blends whilst maintaining acceptable performance. The permanent deformation characteristics of the triple blends were determined and compared using RLT and WT tests.

\section{Materials and Methods}

Different percentages of RG, up to $40 \%$, were triple-blended with CB and CC in this research. The CC utilized was for the upper $(100 \%$ CC) and lower sub-bases, which in the latter case was comprised of up to $50 \% \mathrm{CB}$. All recycled materials for this study were obtained from a major local recycling company in Melbourne, Australia. Particle size distribution testing was conducted following AS 1141.11 "Particle size distribution by sieving" [31]. Sieves were individually weighed before testing to ensure minimal material loss during the testing phase. For the sieving process, a minimum material mass of $3 \mathrm{~kg}$ was utilized, and the resulting particle size distribution curve was plotted for each material. Improved grading provides maximum compacted density for granular material in order to maximize resistance to rutting [5]. Figure 1 illustrates the particle size distributions of the parent materials used in this research along with the upper limits (UL) and lower limits (LL) of the local road authority. 


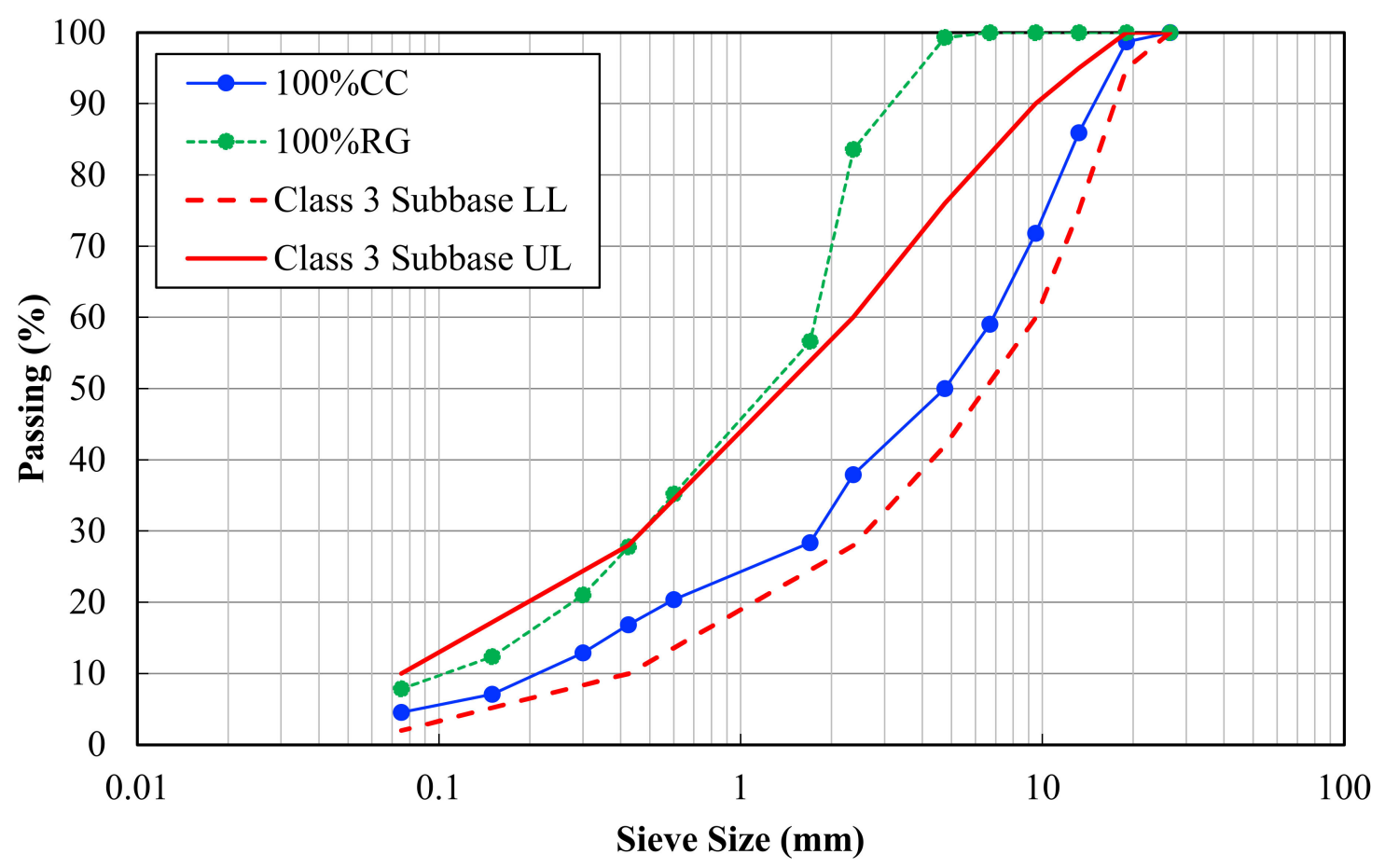

Figure 1. Particle size distribution of the parent materials.

The particle density test was performed for both the fine-fraction AS 1141.5 [32] and coarse-fraction AS 1141.6.1 [33] of all recycled materials. The organic content of each material was determined using ASTM D2974 "Standard test methods for moisture, ash, and organic matter of peat and other organic soils" [34]. The flakiness index test was conducted to evaluate the overall thickness parameters in relation to the material sample size in accordance with AS 1141.15 [35]. Los Angeles (LA) abrasion tests were performed to evaluate the resistance of the parent materials to abrasion following ASTM C131 [36].

The optimum moisture content (OMC) and maximum dry density (MDD) of all the nominated blends being tested were evaluated using the modified compaction method, which was performed based on the AS 1289.5.2.1 [37]. The samples were compacted at varying moisture contents using five separate layers within a metal mold $105 \mathrm{~mm}$ in diameter and $115.5 \mathrm{~mm}$ in height. Once compaction was completed, samples were weighed pre- and post-drying to determine the moisture content. The dry density and moisture content data for the varying samples were then plotted and graphed in order to determine the OMC and MDD for each individual mixture.

The California Bearing Ratio (CBR) tests were performed to determine the soil strength capabilities of mixtures compacted at $98 \% \mathrm{MDD}$ and $100 \% \mathrm{OMC}$, as determined in the "modified compaction" testing. Samples were compacted following AS 1289.6.1.1 "Soil strength and consolidation tests-Standard laboratory method for a remolded specimen" [38]. All nominated blends were compacted in molds $152 \mathrm{~mm}$ in diameter and $117 \mathrm{~mm}$ in height at 100\% MDD and 98\% OMC, as specified by the Australian Standards. Each mixture consisted of 5 separate (scratched) layers and were compacted individually with 56 weighted blows. Once compacted, samples were weighted and then submerged in a water bath for four days prior to testing.

The RLT test was performed to assess the deformation and resilient modulus $\left(\mathrm{M}_{R}\right)$ characteristics of the selected mixtures, following the Austroads Test Method AG:PT/T053 [39]. During the test, samples are exposed to a series of loading cycles to recreate the pavement dynamic loads influenced by moving vehicles [40]. Each sample was compacted at $100 \%$ OMC and MDD within a metal mold $100 \mathrm{~mm}$ in diameter and $200 \mathrm{~mm}$ in height. The mixture compaction consisted of 25 individual blows for each of the 8 (scratched) layers. After compaction, the samples were dried back to $70 \%$ OMC prior to RLT testing. The 
permanent deformation tests were carried out at three loading stages with a constant confining pressure of $50 \mathrm{kPa}$ and deviator stresses of 350, 450, and $550 \mathrm{kPa}$. Each loading cycle consisted of $1 \mathrm{~s}$ of rectangular loading followed by a 2-s resting period. A constant positive minimum deviator stress of $5 \mathrm{kPa}$ was also maintained on top of the sample to exclude the possibility of sudden loading. Fully automated cyclic triaxial equipment with a maximum capacity of $16 \mathrm{kN}$ was used. The axial deformation of the sample was measured at each load cycle by three axial linear variable differential transformers (LVDT) mounted on the loading rod. Confining pressure was applied with confined air and was controlled through an air-pressure transducer. A total of 7 tests were carried out to determine the effect of RG inclusion on the permanent deformation of blends.

WT tests are widely used to assess the rutting sensitivity of crushed material mixes. In WT tests, a slab of material is exposed to rolling passes of a loaded wheel for 1000 cycles. This causes material rutting under the wheel. The rut depth is measured as a function of the number of cycles. For a given number of cycles, the rut depth reached provides a relative assessment of material rutting resistance [41]. The WT test was executed via a real-sized wheel with an inflated tire pressure of $600 \mathrm{kPa}$, applying an axial load of $8 \mathrm{kN}$ onto two samples in accordance with AGP-T054 [42]. The wheel was travelling at a frequency of $0.4 \mathrm{~Hz}$ and had a diameter of $550 \mathrm{~mm}$ and a width of $110 \mathrm{~mm}$. The subsequent load applied by the WT test can therefore cause deformation within the samples, and this information was recorded by an automated laser scanning device. The laser recorded the information at the end of each loading cycle in five specified profiles. The WT test was performed on a compacted sample, which was exposed to the moving wheel acting at different loadings. The subsequent rutting depths were logged at various specified cycles, which achieved an in-depth evaluation of the material's resistance capabilities to rutting [4]. The sample was compacted to $98 \%$ MDD and at $80 \%$ OMC in 6 layers using a segmented roller compactor. The sample had final dimensions of $500 \mathrm{~mm}(\mathrm{~W}) \times 700 \mathrm{~mm}(\mathrm{~L}) \times 300 \mathrm{~mm}(\mathrm{D})$.

\section{Results and Discussion}

Figure 2 illustrates the particle size distributions for all the nominated blends along with the lower and upper limits of Class 3, as specified by the state road authority.

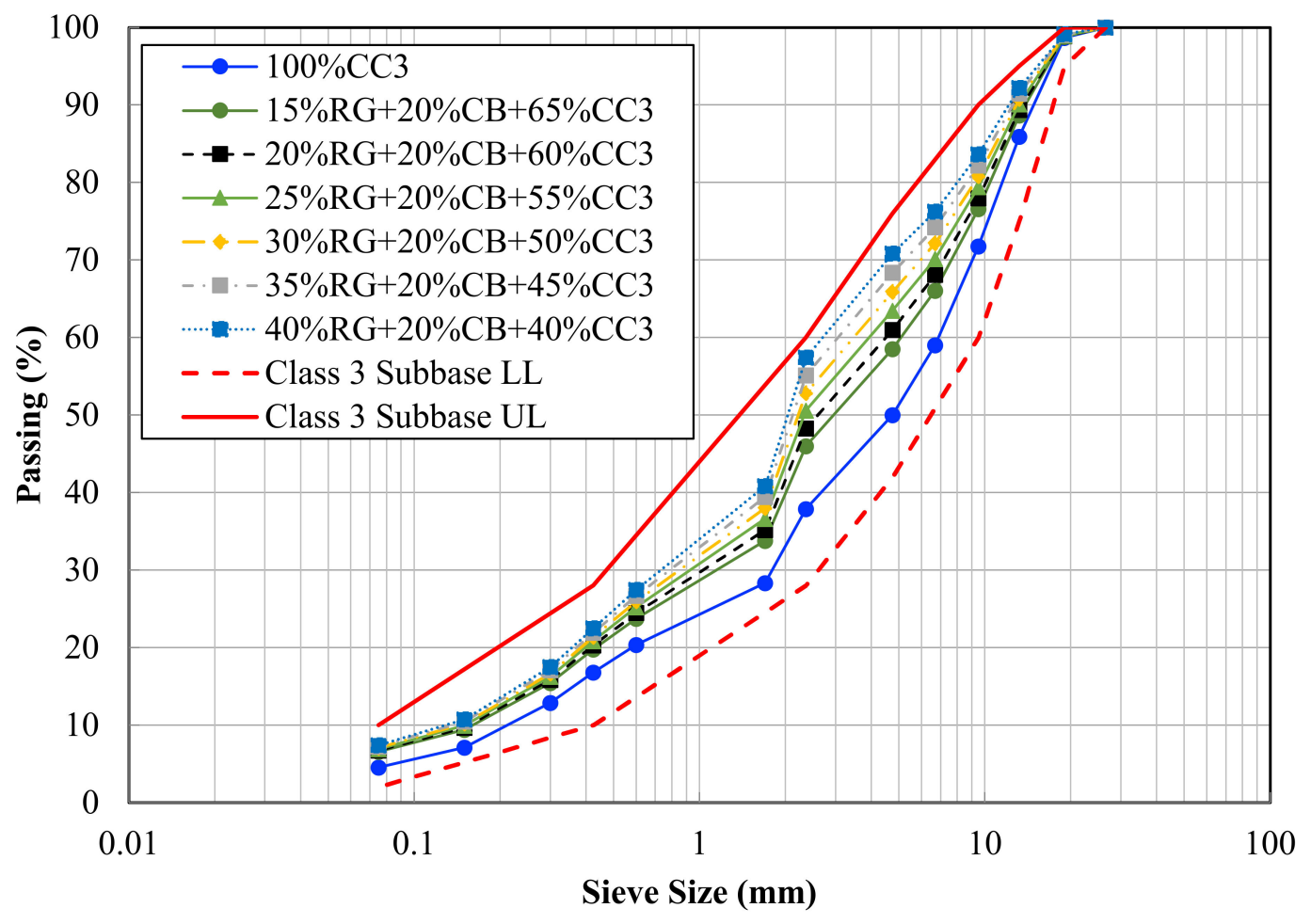

Figure 2. Particle size distribution of the nominated blends. 
The organic content of the $100 \%$ CC was less than 1, and for the $100 \%$ RG it was 1.2 (Table 1). The average apparent particle density from both fine and coarse aggregates of each material was calculated, and they are reported in Table 1.

Table 1. Geotechnical properties of the parent materials.

\begin{tabular}{|c|c|c|c|c|}
\hline Engineering Properties & & $100 \% \mathrm{CC}$ & $100 \%$ RG & Typical Quarry ${ }^{a}$ Materials \\
\hline Fine content & $(\%)$ & 4.5 & 7.8 & $<10$ \\
\hline Sand content & $(\%)$ & 45.5 & 92 & $30-60$ \\
\hline Gravel content & $(\%)$ & 50 & 0.2 & $30-60$ \\
\hline Apparent particle density & $\left(\mathrm{kN} / \mathrm{m}^{3}\right)$ & 2.64 & 2.48 & $>2$ \\
\hline Water absorption & $(\%)$ & 9.8 & $<1$ & $6-12$ \\
\hline Organic content & $(\%)$ & $<1$ & 1.2 & $<5$ \\
\hline Flakiness index & & 19.14 & - & $<35$ \\
\hline LA abrasion loss & $(\%)$ & 28 & - & $<40$ \\
\hline California Bearing Ratio (CBR) & $(\%)$ & 239 & 20 & $>80$ \\
\hline Resilient modulus $\left(\mathrm{M}_{\mathrm{R}}\right)$ & $(\mathrm{MPa})$ & $205-292$ & - & $125-300$ \\
\hline
\end{tabular}

a Data from Maghool, Arulrajah, Horpibulsuk and Du [23].

The $100 \%$ CC had higher particle density compared to the triple blends. A particle is classified as "flaky" when it possesses a least-thickness (dimension) less than $60 \%$ of its mean size, as stated in the AS 1141.15 [35]. The material being analyzed for this test was CC. The mass of all "flaky" particles from each sieve were tallied and compared to that of the initial total mass, allowing the overall flakiness index of the selected material to be determined and reported in Table 1. RG water absorption was measured to be less than $1 \%$, while that of the $100 \%$ CC was calculated to be in the range of typical quarry materials.

The OMC and MDD of the nominated blends were calculated, and are reported in Table 2. There was a direct relationship between OMC and CC percentage; $100 \%$ CC had higher OMC, and $40 \% \mathrm{RG}+20 \% \mathrm{CB}+40 \% \mathrm{CC}$ showed the lowest OMC. The $\mathrm{pH}$ values of all the blends are presented in Table 2 .

Table 2. Engineering properties of the nominated blends.

\begin{tabular}{cccccc}
\hline Blends & pH & OMC (\%) & MDD (kN/m $\left.\mathbf{3}^{\mathbf{3}}\right)$ & CBR (\%) & Permeability (m/s) \\
\hline $100 \%$ CC & 12.4 & 11.5 & 1.96 & $230-248$ & $1.05 \times 10^{-7}$ \\
$15 \%$ RG + 20\% CB + 65\% CC & 11.87 & 10.6 & 1.98 & $220-257$ & $4.57 \times 10^{-7}$ \\
$20 \%$ RG + 20\% CB + 60\% CC & 11.78 & 10.7 & 1.97 & $192-228$ & $1.39 \times 10^{-7}$ \\
$25 \%$ RG + 20\% CB + 55\% CC & 11.64 & 10.7 & 1.97 & $167-182$ & $2.15 \times 10^{-7}$ \\
$30 \%$ RG + 20\% CB + 50\% CC & 11.51 & 10.5 & 1.96 & $165-202$ & $9.76 \times 10^{-7}$ \\
$35 \%$ RG + 20\% CB + 45\% CC & 11.37 & 10.4 & 1.96 & $131-157$ & $1.78 \times 10^{-6}$ \\
$40 \%$ RG + 20\% CB + 40\% CC & 11.23 & 10.0 & 1.96 & $116-147$ & $4.34 \times 10^{-6}$ \\
\hline
\end{tabular}

The $\mathrm{pH}$ range for the triple blends was 11.23-12.23, which suggests that the parent materials and the triple blends were all alkaline, which is similar to previous studies' results on the same materials [20]. The LA abrasion test is a commonly specified test for evaluating the resistance of aggregates to abrasion and impact forces. The LA abrasion loss in $100 \%$ $\mathrm{CC}$ was lower than the maximum LA abrasion value of 40 set by local road authorities for sub-base applications [43].

The permeability results of the nominated triple blends are presented in Table 2 . These values describe the nominated blends as a very low-permeability material, based on the hydraulic conductivity classification chart introduced by Terzaghi et al. [44]. When RG was more than $30 \%$, the mixes showed relatively higher permeability due to the high content of non-cohesive fines. The CBR value of $100 \%$ CC was high and varied from $229 \%$ to $239 \%$. The results of CBR tests for the parent materials are summarized in Table 1 and for all the blends in Table 2. The test results indicate that the CBR value of the triple blends 
decreased with the addition of RG. All the blends met the local road authority requirement for minimum CBR value of $80 \%$ [43].

The results of RLT tests were analyzed to determine the performance of unbound $\mathrm{RG} / \mathrm{CB} / \mathrm{CC}$ triple blends under real traffic loading conditions. Figure 3 shows the results of the resilient modulus test at different stress stages.

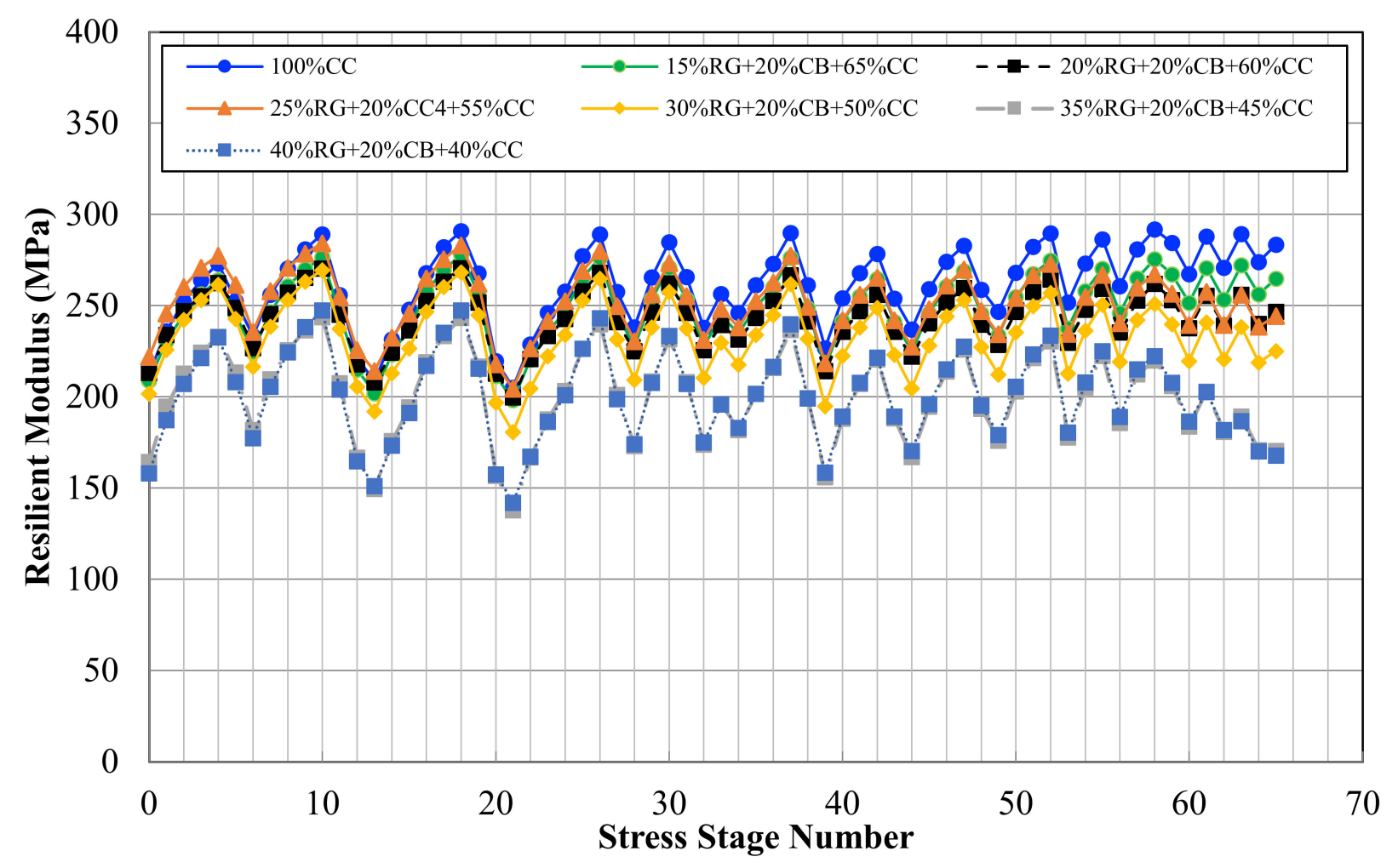

Figure 3. Resilient modulus of the nominated blends.

Based on the results, 100\% CC presented the highest resilient modulus range. The permanent deformation test was performed under $50 \mathrm{kPa}$ confining pressure at three different loading stages. Each loading stage comprised 10,000 repeats, which summed to 30,000 cycles for the completion of the permanent deformation test. Figure 4 demonstrates the permanent deformation results for all the blends.

The $15 \%$ RG $+20 \%$ CB $+65 \%$ CC blend demonstrated the lowest permanent deformation after $100 \%$ CC. The results of RLT tests are summarized in Table 3 and were in ranges reported in previous studies by Arulrajah et al. [45].

Table 3. Resilient modulus and permanent strain testing for the nominated blends.

\begin{tabular}{|c|c|c|c|c|}
\hline \multirow{2}{*}{ Blends } & \multirow{2}{*}{$\mathrm{M}_{\mathrm{R}}(\mathrm{MPa})$} & \multicolumn{3}{|c|}{ Permanent Strain at the End of Each Stage, Microstrain } \\
\hline & & Stage 1 & Stage 2 & Stage 3 \\
\hline $100 \%$ CC & $205-292$ & 995 & 1282 & 1596 \\
\hline $15 \% R G+20 \% C B+35 \% C C$ & $198-278$ & 1082 & 1392 & 1703 \\
\hline $20 \% \mathrm{RG}+20 \% \mathrm{CB}+40 \% \mathrm{CC}$ & $200-271$ & 1194 & 1492 & 1804 \\
\hline $25 \% \mathrm{RG}+20 \% \mathrm{CB}+35 \% \mathrm{CC}$ & $204-284$ & 1154 & 1443 & 1755 \\
\hline $30 \% R G+20 \% C B+30 \% C C$ & $181-270$ & 1220 & 1534 & 1867 \\
\hline $35 \% \mathrm{RG}+20 \% \mathrm{CB}+25 \% \mathrm{CC}$ & $138-244$ & 1406 & 1746 & 2110 \\
\hline $40 \% R G+20 \% C B+20 \% C C$ & $142-247$ & 1383 & 1723 & 2086 \\
\hline
\end{tabular}




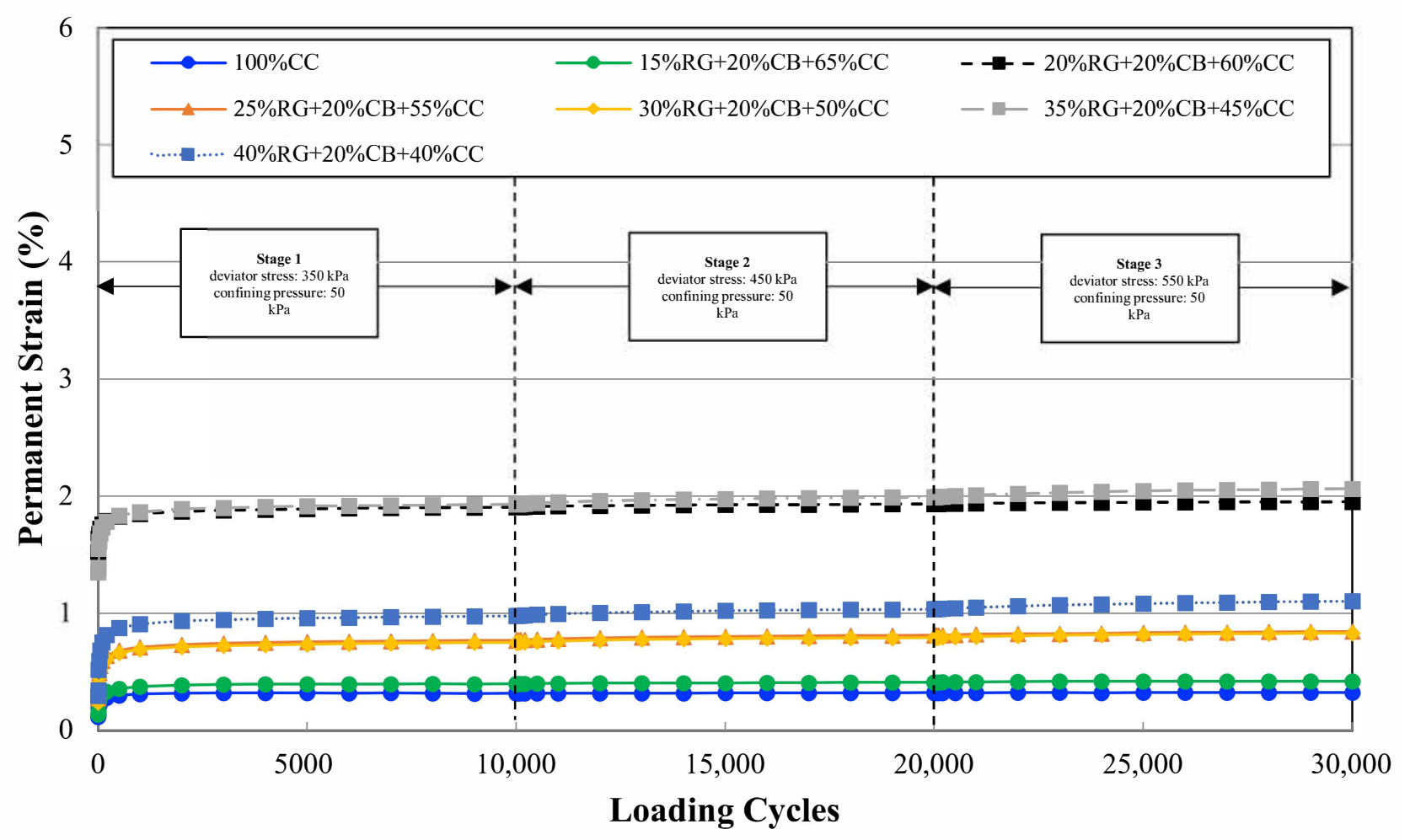

Figure 4. Permanent deformation of the nominated blends.

There was a trend of higher permanent deformation with increasing RG content, but a couple of anomalies were noticed within the seven blends. Based on the RLT assessment, $15 \%$ RG performed the best among all the blends containing RG. Thus, the 15\% RG $+20 \%$ $\mathrm{CB}+65 \%$ CC blend was chosen for the WT test. Austroads [39] specifies a strain limit of $2 \%$ under permanent strain loading. All the samples experienced lower values than this limit, except for $35 \% \mathrm{RG}+20 \% \mathrm{CB}+45 \% \mathrm{CC}$ at stage 3 of loading. Among those tested, the blend containing $15 \% \mathrm{RG}+20 \% \mathrm{CB}+65 \% \mathrm{CC}$ had a similar rate of permanent deformation to $100 \%$ CC after the first 3000 cycles at each loading stage. Therefore, this blend was chosen for further assessment under the WT loading condition.

A WT test was conducted on the $15 \% \mathrm{RG}+20 \% \mathrm{CB}+65 \% \mathrm{CC}$ sample in a temperaturecontrolled chamber with a set temperature of $25{ }^{\circ} \mathrm{C}$. The sample size was $500 \mathrm{~mm}(\mathrm{~W}) \times$ $700 \mathrm{~mm}(\mathrm{~L}) \times 300 \mathrm{~mm}(\mathrm{D})$. The sample was compacted inside the mold at $80 \%$ OMC in six layers using a segmented roller compactor with a maximum load capacity of $30 \mathrm{kN}$, to reach $98 \%$ MDD. Figure 5 shows the different stages of WT sample preparation.

The sample was dried back to $70 \%$ OMC for the WT test. The sample was sealed with epoxy before the start of the test. The sample was mounted to the temperature control chamber $\left(25^{\circ} \mathrm{C}\right)$ for WT testing. The rutting was recorded using a laser at specific sections (five) during the test to determine the transversal deformation. Figure 6a shows the WT test setup and Figure $6 \mathrm{~b}$ shows the laser rut sections and measurement area. The WT test was carried out for 40,000 cycles and the mean deformation was recorded after each loading cycle, unless the sample deformed more than $18 \mathrm{~mm}$ during the test and failed to meet standards according to Austroads AGP-T054 [42]. 


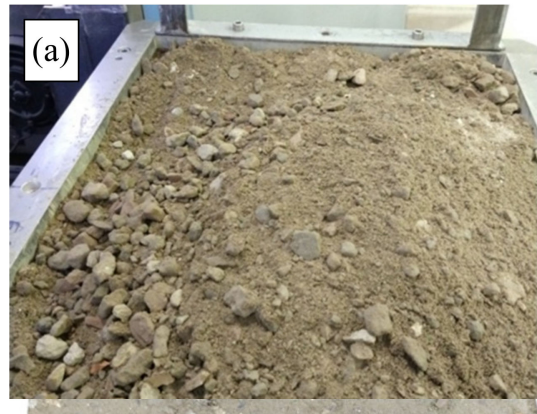

(d)

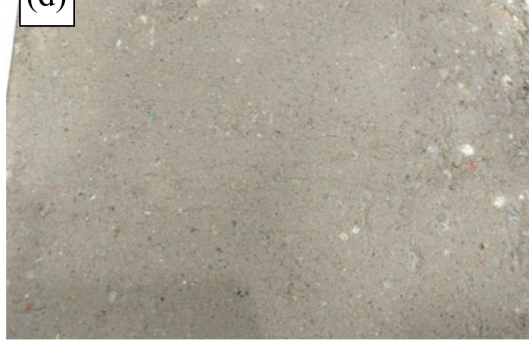

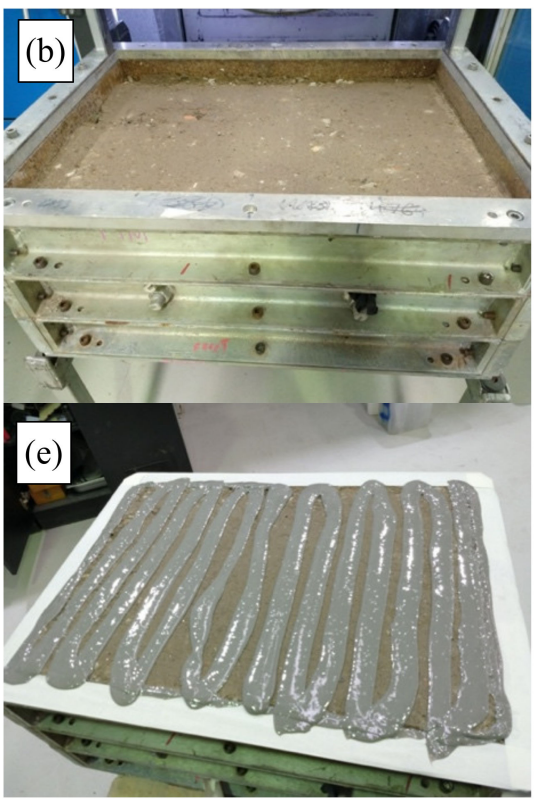

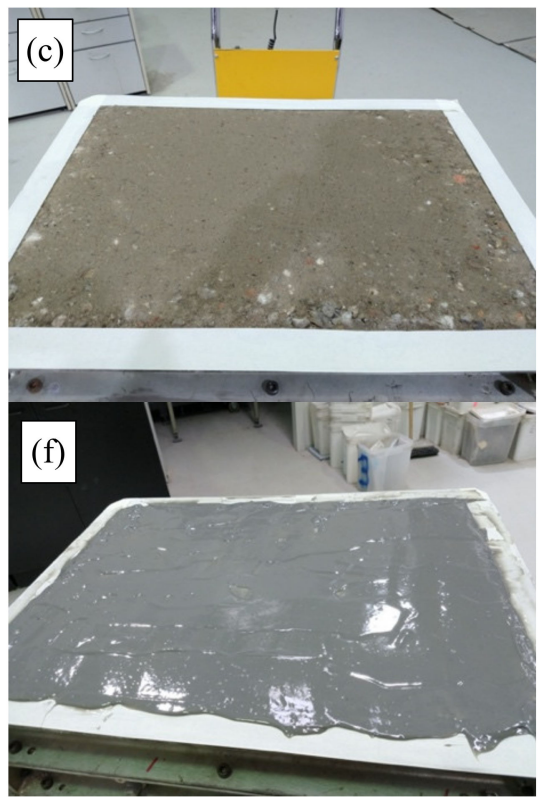

Figure 5. Specimen preparation prior to wheel-tracker (WT) testing (a) sample preparation, (b,c) compaction, (d) Specimen surface, (e) applying epoxy and (f) sealed sample.

The $15 \%$ RG $+20 \%$ CB $+65 \%$ CC sample did not fail after 40,000 cycles of the WT test. The maximum surface deformation and maximum rut depth data are presented in Table 4 and plotted in Figure 7.

Table 4. Overall mean surface deformation and overall maximum rut depth data for $15 \% \mathrm{RG}+20 \% \mathrm{CB}+65 \% \mathrm{CC}$.

\begin{tabular}{|c|c|c|c|c|c|c|c|c|c|c|c|c|}
\hline \multirow{4}{*}{$\begin{array}{c}\text { Number of } \\
\text { Cycles (N) }\end{array}$} & \multicolumn{5}{|c|}{ Mean Surface Deformation } & \multirow{4}{*}{ 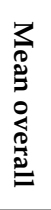 } & \multicolumn{5}{|c|}{ Maximum Rut Depth } & \multirow{4}{*}{ 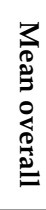 } \\
\hline & \multicolumn{5}{|c|}{ Cross Section } & & \multicolumn{5}{|c|}{ Cross Section } & \\
\hline & 1 & 2 & 3 & 4 & 5 & & 1 & 2 & 3 & 4 & 5 & \\
\hline & $\begin{array}{c}-150 \\
\mathrm{~mm}\end{array}$ & $\begin{array}{l}-75 \\
\mathrm{~mm}\end{array}$ & $\begin{array}{c}0 \\
\mathrm{~mm}\end{array}$ & $\begin{array}{l}+75 \\
\mathrm{~mm}\end{array}$ & $\begin{array}{l}+150 \\
\mathrm{~mm}\end{array}$ & & $\begin{array}{l}-150 \\
\mathrm{~mm}\end{array}$ & $\begin{array}{l}-75 \\
\mathrm{~mm}\end{array}$ & $\begin{array}{c}0 \\
\mathrm{~mm}\end{array}$ & $\begin{array}{l}+75 \\
\mathrm{~mm}\end{array}$ & $\begin{array}{l}+150 \\
\mathrm{~mm}\end{array}$ & \\
\hline 0 & 0.0 & 0.0 & 0.0 & 0.0 & 0.0 & 0.0 & 0.0 & 0.0 & 0.0 & 0.0 & 0.0 & 0.0 \\
\hline 10 & 0.8 & 0.8 & -0.2 & 0.0 & 0.2 & 0.3 & 2.7 & 2.9 & 0.8 & 1.0 & 1.0 & 1.7 \\
\hline 50 & 1.0 & 1.0 & 0.0 & 0.1 & 0.3 & 0.5 & 3.0 & 3.4 & 1.4 & 1.2 & 1.4 & 2.1 \\
\hline 100 & 1.1 & 1.1 & 0.0 & 0.3 & 0.5 & 0.6 & 3.3 & 3.5 & 1.6 & 1.6 & 1.8 & 2.3 \\
\hline 200 & 1.0 & 1.1 & 0.0 & 0.3 & 0.5 & 0.6 & 3.6 & 3.8 & 1.5 & 2.0 & 1.9 & 2.6 \\
\hline 300 & 1.0 & 1.1 & 0.1 & 0.4 & 0.6 & 0.6 & 3.5 & 3.7 & 1.7 & 1.9 & 2.1 & 2.6 \\
\hline 500 & 1.1 & 1.2 & 0.2 & 0.7 & 0.9 & 0.8 & 3.6 & 4.0 & 2.1 & 2.4 & 2.5 & 2.9 \\
\hline 1000 & 1.1 & 1.3 & 0.3 & 0.8 & 0.7 & 0.8 & 3.5 & 4.1 & 1.6 & 2.3 & 1.4 & 2.6 \\
\hline 2000 & 1.1 & 1.3 & 0.3 & 0.9 & 0.7 & 0.9 & 3.5 & 3.7 & 2.2 & 2.6 & 2.3 & 2.9 \\
\hline 3000 & 1.1 & 1.4 & 0.4 & 1.0 & 0.6 & 0.9 & 3.6 & 3.8 & 2.3 & 2.6 & 2.2 & 2.9 \\
\hline 4000 & 1.1 & 1.4 & 0.4 & 1.0 & 0.6 & 0.9 & 3.7 & 3.9 & 2.4 & 2.7 & 2.1 & 3.0 \\
\hline 5000 & 1.2 & 1.4 & 0.4 & 1.0 & 0.6 & 0.9 & 3.8 & 4.2 & 2.4 & 2.8 & 2.4 & 3.1 \\
\hline 10,000 & 1.2 & 1.4 & 0.5 & 1.0 & 0.6 & 0.9 & 3.7 & 4.2 & 2.7 & 3.1 & 2.3 & 3.2 \\
\hline 15,000 & 1.2 & 1.4 & 0.5 & 1.1 & 0.5 & 0.9 & 3.7 & 4.1 & 2.5 & 3.1 & 2.4 & 3.2 \\
\hline 20,000 & 1.2 & 1.4 & 0.5 & 1.1 & 0.4 & 0.9 & 3.9 & 4.1 & 3.0 & 3.0 & 2.1 & 3.2 \\
\hline 30,000 & 1.1 & 1.4 & 0.5 & 1.0 & 0.4 & 0.9 & 3.9 & 4.3 & 2.8 & 3.2 & 2.3 & 3.3 \\
\hline 40,000 & 1.0 & 1.4 & 0.4 & 1.0 & 0.4 & 0.9 & 3.8 & 4.5 & 2.9 & 3.2 & 2.4 & 3.4 \\
\hline
\end{tabular}




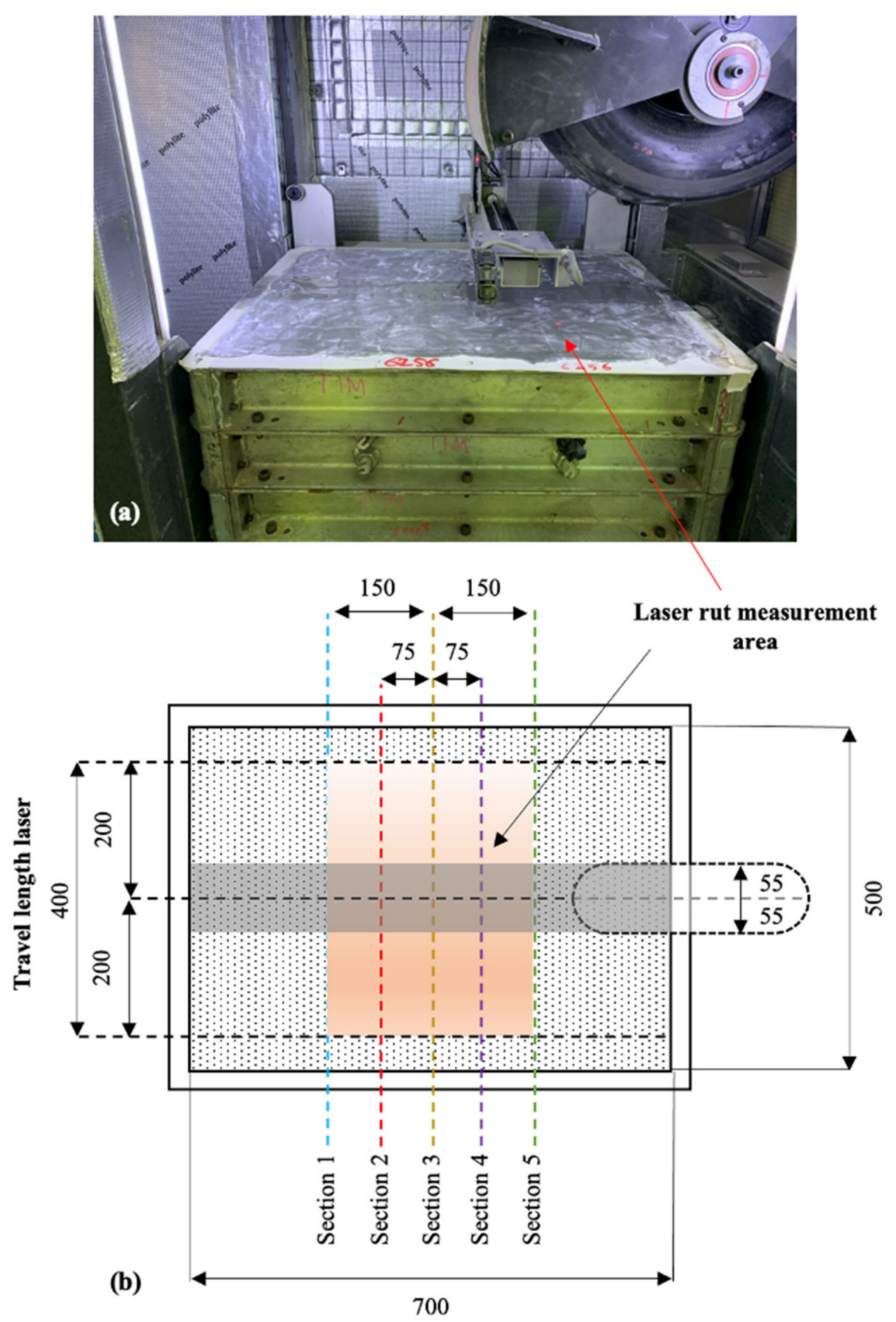

Figure 6. (a) Wheel-tracking test setup and (b) details and measurement sections, all in mm [4].

For a better understanding, the maximum surface deformation and maximum rut depth in Figure $7 \mathrm{a}, \mathrm{b}$ are presented against the number of loading cycles in decimal and logarithmic scale, respectively.

Figure 8 presents profile data of all five cross sections at different cycles for $15 \%$ RG $+20 \%$ CB $+65 \%$ CC. As shown in this figure, the vertical surface deformation increased gradually as the number of cycles increased. 

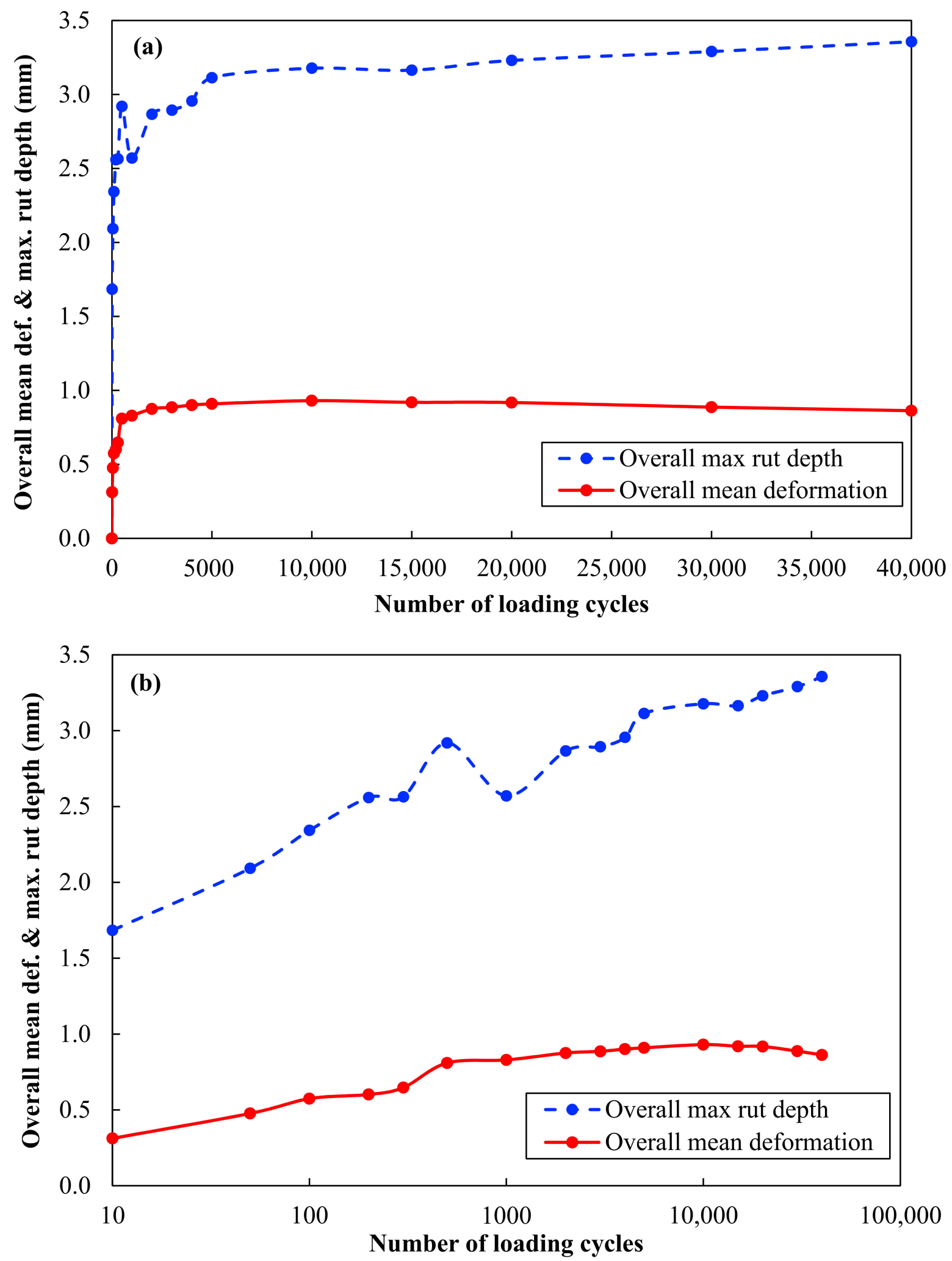

Figure 7. Overall mean surface deformation data and maximum rut depth data for $15 \% \mathrm{RG}+20 \% \mathrm{CB}+65 \% \mathrm{CC}$ : (a) Decimal scale and (b) semi-logarithmic scale. 


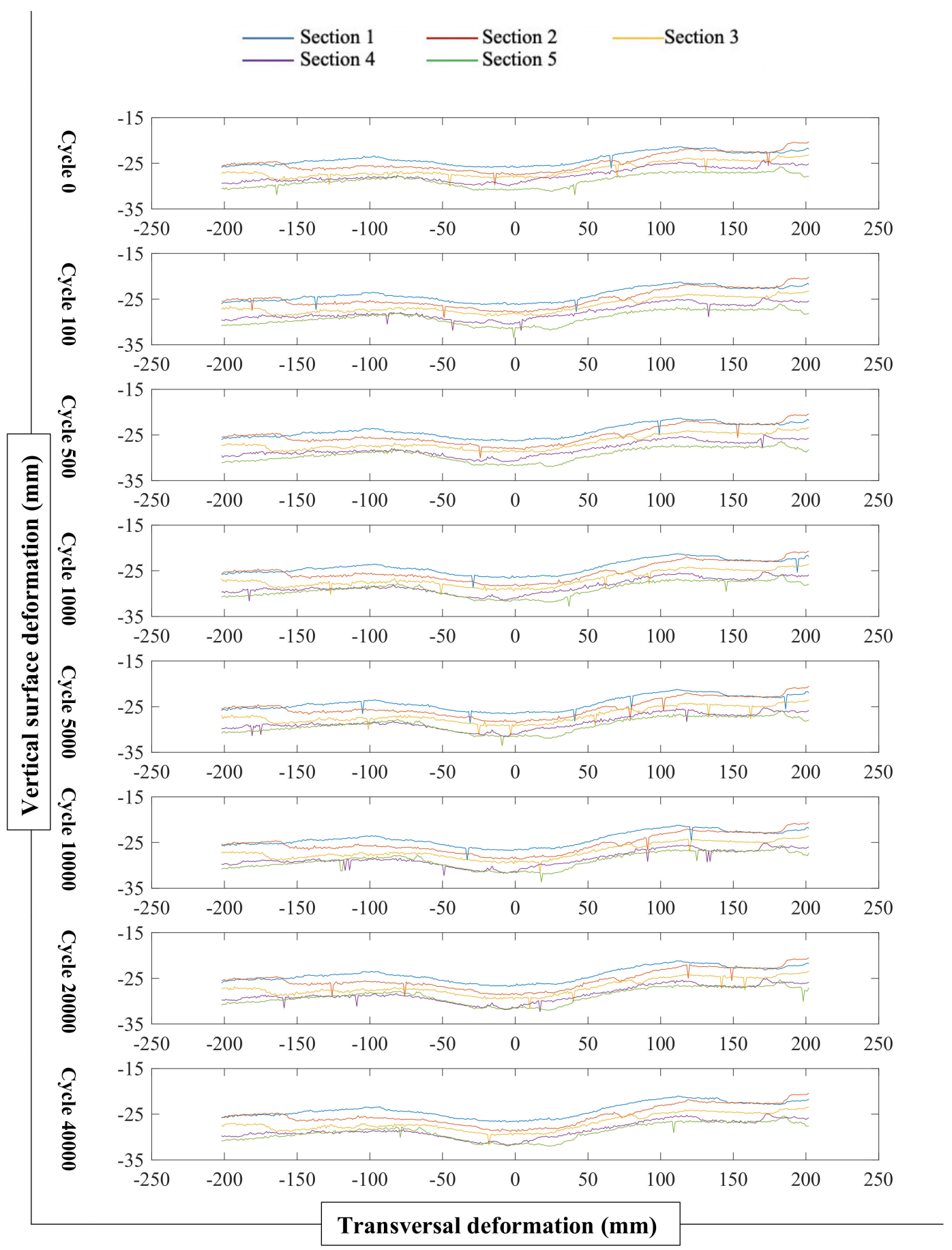

Figure 8. Profile data of all cross sections at different cycles for $15 \% \mathrm{RG}+20 \% \mathrm{CB}+65 \% \mathrm{CC}$.

Figure 9 shows the rutting measurement and density check after the WT test. The WT results showed that the $15 \% \mathrm{RG}+20 \% \mathrm{CB}+65 \% \mathrm{CC}$ sample, with maximum surface deformation of $0.9 \mathrm{~mm}$ and maximum rut depth of $3.4 \mathrm{~mm}$, performed well after 40,000 cycles and met the Austroads requirements for base/sub-base applications. Austroads [42] specifies a mean deformation of $18 \mathrm{~mm}$ as a complete failure of the slab. The mean deformation of sample $15 \%$ RG $+20 \%$ CB $+65 \%$ CC in Table 4 was measured to be far below this threshold. 

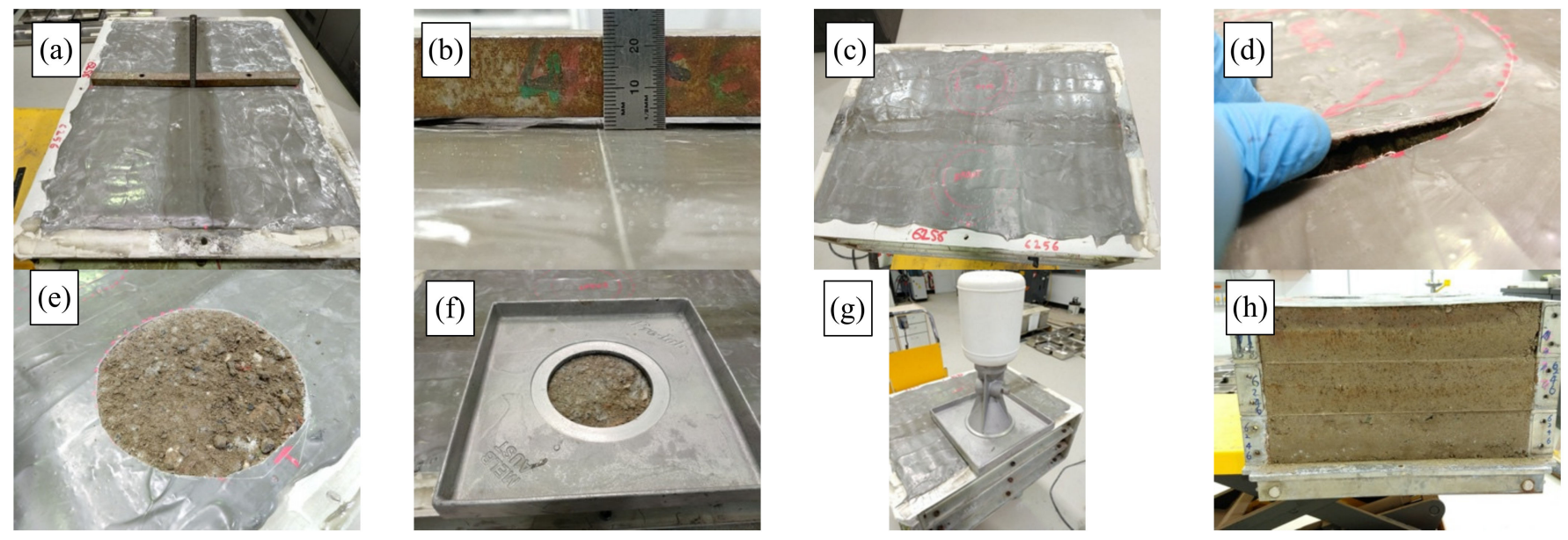

Figure 9. Post WT test rutting and density measurements. (a) after test, (b) final rut measurement, (c) after test specimen, (d), (e,f) sampling after test, (g) density check and (h) layers after test.

\section{Conclusions}

The geotechnical characteristics of unbound RG/CB/CC blends consisting of up to $40 \%$ RG and $20 \%$ CB with CC were evaluated. The particle-size distribution curve of all blends was within the upper and lower limits of Class 3 set by local and state road authority. The CBR values of all blends were well above the minimum requirements specified by the local road authority for blends used in pavement applications.

The results of RLT tests were used to ascertain the performance of unbound RG/CB/CC blends under simulated traffic loading conditions. Based on the RLT assessment, all the nominated blends were found to provide the required resilient modulus value for use as base and sub-base materials. The 15\% RG $+20 \%$ CB $+65 \%$ CC blend demonstrated the lowest permeant deformation after $100 \%$ CC under long-term repeated loading. Thus, the $15 \%$ RG $+20 \%$ CB $+65 \%$ CC blend was chosen for the WT test.

The WT results confirmed that the triple blends with $15 \%$ RG did not fail during the test. With maximum surface deformation of $0.9 \mathrm{~mm}$ and maximum rut depth of $3.4 \mathrm{~mm}$, the sample performed well after 40,000 cycles and comfortably met the Austroads requirement of $18 \mathrm{~mm}$ for use in pavement applications.

Based on the engineering properties and permanent deformation results, up to $15 \%$ RG can be primarily suggested for incorporation as an accompanying material in unbound roadwork applications. The blends 25\% RG $+20 \% \mathrm{CB}+55 \% \mathrm{CC}$ and $30 \% \mathrm{RG}+20 \% \mathrm{CB}$ $+50 \%$ CC exhibited relatively low permanent deformation in the RLT assessment. Thus, subject to the outcomes of future field testing, there may be the potential to increase the percentage of RG added in the blends up to $30 \%$ for upcoming projects, as well as to alleviate concerns regarding an increase in the uptake of recycled materials into the marketplace.

Author Contributions: Conceptualization, F.M., A.A., S.H. and M.S.; methodology, F.M. and M.S.; software, F.M. and A.A.; validation, F.M., A.A. and S.H.; formal analysis, F.M. and M.S.; investigation, F.M. and A.A.; resources, F.M. and A.A.; writing-original draft preparation, F.M., S.H., A.A. and M.S.; writing—review and editing, F.M., A.A., S.H. and M.S.; supervision, A.A. and S.H.; funding acquisition, F.M. and A.A. All authors have read and agreed to the published version of the manuscript.

Funding: This research project was funded by Sustainability Victoria (Project ID: C-110066) and supported by Department of Transport (VicRoads) and the Alex Fraser Group.

Institutional Review Board Statement: Not applicable.

Informed Consent Statement: Not applicable. 
Data Availability Statement: The data presented in this study are available on request from the corresponding author. The data are not publicly available due to Sustainability Victoria regulations.

Acknowledgments: This research project was technically supported by Department of Transport (VicRoads) and the Alex Fraser Group.

Conflicts of Interest: The authors declare no conflict of interest.

\section{References}

1. Ardalan, N.; Wilson, D.J.; Larkin, T.J. Analyzing the Application of Different Sources of Recycled Concrete Aggregate for Road Construction. Transp. Res. Rec. J. Transp. Res. Board 2020, 2674, 300-308. [CrossRef]

2. Maghoolpilehrood, F.; Disfani, M.M.; Arulrajah, A. Geotechnical Characteristics of Aged Biosolids Stabilized with Cement and Lime. Aust. Geomech. J. 2013, 48, 113-120.

3. Senate, T. Environment and Communications References Committee: Never Waste a Crisis: The Waste and Recycling Industry in Australia; Parliament House Canberra ACT: Canberra, Australia, 2018.

4. Arulrajah, A.; Arulrajah, A.; Mohammadinia, A.; Mirzababaei, M.; Horpibulsuk, S. Wheel tracker testing of recycled concrete and tyre aggregates in Australia. Geotech. Res. 2020, 7, 49-57. [CrossRef]

5. Brown, S.F.; Chan, F.W.K. Reduced rutting in unbound granular pavement layers through improved grading design. In Institution of Civil Engineers-Transport; Thomas Telford Ltd.: London, UK, 1996; Volume 117, pp. 40-49.

6. Disfani, M.M.; Arulrajah, A.; Ali, M.M.Y.; Bo, M.W. Fine recycled glass: A sustainable alternative to natural aggregates. Int. J. Geotech. Eng. 2011, 5, 255-266. [CrossRef]

7. Ali, M.M.Y.; Arulrajah, A.; Disfani, M.M.; Piratheepan, J. Suitability of Using Recycled Glass-Crushed Rock Blends for Pavement Subbase Applications. Geo-Frontiers 2011, 2011, 1325-1334.

8. Debieb, F.; Kenai, S. The use of coarse and fine crushed bricks as aggregate in concrete. Constr. Build. Mater. 2008, 22, 886-893. [CrossRef]

9. Suddeepong, A.; Sari, N.; Horpibulsuk, S.; Chinkulkijniwat, C.; Arulrajah, A. Interface shear behaviors between recycled concrete aggregate and geogrid for pavement applications. Int. J. Pavement Eng. 2018, 21, 228-235. [CrossRef]

10. Demir, I.; Orhan, M. Reuse of waste bricks in the production line. Build. Environ. 2003, 38, 1451-1455. [CrossRef]

11. Aatheesan, T.; Arulrajah, A.; Bo, M.W.; Vuong, B.; Wilson, J.L. Crushed brick blends with crushed rock for pavement systems. In Institution of Civil Engineers-Waste and Resource Management; Thomas Telford Ltd.: London, UK, 2010; Volume 163, pp. $29-35$.

12. Sivakugan, N.; Arulrajah, A.; Bo, M.W. Laboratory Testing of Soils, Rocks and Aggregates, 1st ed.; J. Ross Publishing: Fort Lauderdale, FL, USA, 2011.

13. Arulrajah, A.; Ali, M.M.Y.; Piratheepan, J.; Bo, M.W. Geotechnical Properties of Waste Excavation Rock in Pavement Subbase Applications. J. Mater. Civ. Eng. 2012, 24, 924-932. [CrossRef]

14. Sobhan, K. Innovative fracture-resistant construction material from C\&D waste aggregate, fly ash and recycled plastics. Int. J. Environ. Pollut. 2007, 31, 304. [CrossRef]

15. Consoli, N.C.; Montardo, J.P.; Prietto, P.D.M.; Pasa, G.S. Engineering Behavior of a Sand Reinforced with Plastic Waste. J. Geotech. Geoenvironmental Eng. 2002, 128, 462-472. [CrossRef]

16. Hoy, M.; Rachan, R.; Horpibulsuk, S.; Arulrajah, A.; Mirzababaei, M. Effect of wetting-drying cycles on compressive strength and microstructure of recycled asphalt pavement-Fly ash geopolymer. Constr. Build. Mater. 2017, 144, 624-634. [CrossRef]

17. Puppala, A.J.; Hoyos, L.R.; Potturi, A.K. Resilient Moduli Response of Moderately Cement-Treated Reclaimed Asphalt Pavement Aggregates. J. Mater. Civ. Eng. 2011, 23, 990-998. [CrossRef]

18. Suthagaran, V.; Arulrajah, A.; Bo, M.W. Geotechnical laboratory testing of biosolids. Int. J. Geotech. Eng. 2010, 4, 407-415. [CrossRef]

19. Arulrajah, A.; Maghoolpilehrood, F.; Disfani, M.M.; Horpibulsuk, S. Spent coffee grounds as a non-structural embankment fill material: Engineering and environmental considerations. J. Clean. Prod. 2014, 72, 181-186. [CrossRef]

20. Saberian, M.; Li, J.; Setunge, S. Evaluation of permanent deformation of a new pavement base and subbase containing unbound granular materials, crumb rubber and crushed glass. J. Clean. Prod. 2019, 230, 38-45. [CrossRef]

21. Arulrajah, A.; Mohammadinia, A.; Maghool, F.; Horpibulsuk, S. Tire derived aggregates as a supplementary material with recycled demolition concrete for pavement applications. J. Clean. Prod. 2019, 230, 129-136. [CrossRef]

22. Arulrajah, A.; Horpibulsuk, S.; Maghoolpilehrood, F.; Samingthong, W.; Du, Y.-J.; Shen, S.-L. Evaluation of Interface Shear Strength Properties of Geogrid Reinforced Foamed Recycled Glass Using a Large-Scale Direct Shear Testing Apparatus. Adv. Mater. Sci. Eng. 2015, 2015, 1-8. [CrossRef]

23. Maghool, F.; Arulrajah, A.; Horpibulsuk, S.; Du, Y.-J. Laboratory Evaluation of Ladle Furnace Slag in Unbound PavementBase/Subbase Applications. J. Mater. Civ. Eng. 2017, 29, 04016197. [CrossRef]

24. Maghool, F.; Arulrajah, A.; Horpibulsuk, S.; Mohajerani, A. Engineering and Leachate Characteristics of Granulated Blast-Furnace Slag as a Construction Material. J. Mater. Civ. Eng. 2020, 32, 04020153. [CrossRef]

25. Maghool, F.; Arulrajah, A.; Du, Y.; Horpibulsuk, S.; Chinkulkijniwat, A. Environmental impacts of utilizing waste steel slag aggregatesas recycled road construction materials. Clean Technol. Environ. Policy 2016, 19, 949-958. [CrossRef] 
26. Amlashi, S.M.H.; Vaillancourt, M.; Carter, A.; Bilodeau, J.-P. Resilient modulus of pavement unbound granular materials containing recycled glass aggregate. Mater. Struct. 2018, 51, 89. [CrossRef]

27. Arulrajah, A.; Piratheepan, J.; Aatheesan, T.; Bo, M.W. Geotechnical Properties of Recycled Crushed Brick in Pavement Applications. J. Mater. Civ. Eng. 2011, 23, 1444-1452. [CrossRef]

28. Disfani, M.M.; Arulrajah, A.; Haghighi, H.; Mohammadinia, A.; Horpibulsuk, S. Flexural beam fatigue strength evaluation of crushed brick as a supplementary material in cement stabilized recycled concrete aggregates. Constr. Build. Mater. 2014, 68, 667-676. [CrossRef]

29. Disfani, M.; Arulrajah, A.; Bo, M.W.; Sivakugan, N. Environmental risks of using recycled crushed glass in road applications. J. Clean. Prod. 2012, 20, 170-179. [CrossRef]

30. Arulrajah, A.; Piratheepan, J.; Ali, M.M.Y.; Bo, M.W. Geotechnical Properties of Recycled Concrete Aggregate in Pavement Sub-Base Applications. Geotech. Test. J. 2012, 35, 103402. [CrossRef]

31. AS. Method for Sampling and Testing Aggregates_Particle Size Distribution by Sieving; Australian Standard: Sydney, Australia, 1996; Australian Standard 1141.11.

32. AS. Particle Density and Water Absorption of Fine Aggregate; Australian Standard: Sydney, Australia, 2000; Australian Standard 1141.5.

33. AS. Particle Density and Water Absorption of Coarse Aggregate-Weighing-in-Water Method; Australian Standard: Sydney, Australia, 2000; Australian Standard 1141.6.1.

34. ASTM. Standard Test Methods for Moisture, Ash, and Organic Matter of Peat and Other Organic Soils; ASTM International: West Conshohocken, PA, USA, 2007; ASTM Standard D2974.

35. AS. Methods for Sampling and Testing Aggregates-Method 15: Flakiness Index; Australian Standard: Sydney, Australia, 1999; Australian standard AS 1141.15.

36. ASTM. Standard Test Method for Resistance to Degradation of Small-Size Coarse Aggregate by Abrasion and Impact in the Los Angeles Machine; ASTM International: West Conshohocken, PA, USA, 2006; ASTM Standard C131.

37. AS. Soil Compaction and Density Tests_Determination of the Dry Density/Moisture Content Relation of a Soil Using Modified Compactive Effort; Australian Standard: Sydney, Australia, 2003; Australian Standard 1289.5.2.1.

38. AS. Determination of the California Bearing Ratio of a Soil—Standard Laboratory Method for a Remoulded Specimen; Australian Standard: Sydney, Australia, 1998; Australian Standard 1289.6.1.1.

39. Austroads. Commentary to AG:PT/T053, Determination of Permanent Deformation and Resilient Modulus Characteristics of Unbound Granular Materials Under Drained Conditions; Austroads: Sydney, Australia, 2007; p. 29.

40. Saberian, M.; Li, J.; Boroujeni, M.; Law, D.W.; Li, C. Application of demolition wastes mixed with crushed glass and crumb rubber in pavement base/subbase. Resour. Conserv. Recycl. 2020, 156, 104722. [CrossRef]

41. Bodin, D.; Grenfell, J.R.; Collop, A.C. Comparison of Small and Large Scale Wheel Tracking Devices. Road Materials and Pavement Design. ICAM 2009, 10, 295-325. [CrossRef]

42. Austroads. AGTP-T054: Determination of Permanent Deformation Characteristics of Unbound Granular Materials by the Wheel-Tracking Test; Austroads: Sydney, Australia, 2015.

43. VicRoads. Guide to General Requirements for Unbound Pavement Materials; VicRoads: Melbourne, Australia, 1998 ; Volume 39.

44. Terzaghi, K.; Peck, R.; Mesri, G. Soil Mechanics in Engineering Practice; John Wiley \& Sons: New York, NY, USA, 1996.

45. Arulrajah, A.; Maghool, F.; Newman, G.; Haghighi, H.; Horpibulsuk, S. Cement-treated recycled glass and crushed rock blends: Modulus of rupture and stiffness properties. Int. J. Pavement Eng. 2020, 10, 1-11. [CrossRef] 